\title{
The impact of government intervention in Dollar stabilization on the economic perceptions of investors in Pakistan
}

\author{
Zain ul abideen \\ Mba Fondation University Rawalpindi Campus
}

\begin{abstract}
Through this research the case of Pakistan economy has been selected. The focus is on seeing the impact that government intervention in dollar stabilization leads to as far as the perceptions of investors are concerned. The perceptions of investors for this case are studied through two proxies. First being the returns on Karachi Stock Index and second being the changes in the foreign direct investment in Pakistan. The results show that dollar intervention does have a fruitful impact on the foreign investments in the country as a decline in the value of dollars sees a growth in the foreign direct investment. Overall the results show that the economy of Pakistan needs and supports the intervention by the government to take corrective actions as it is not observed to be able to correct itself through macroeconomic fundamentals.
\end{abstract}

\section{Introduction}

Whatever the state of an economy may be, there are a number of factors that influence the economic decision making of an investor (Masini and Menichetti, 2012). Research and development in the field of finance has identified a number of factors that may impact the process of financial decision making however there is still a long way to go as far as comprehensive information about the perceptions of investors and the impact that they have on the buying and selling decisions of the organizations are concerned (Turskis et al, 2011 and Hsu et al, 2012). This research has focused on a complex relationship between the government interventions in foreign exchange stabilization and the impact that such activities have on the perceptions of the investors (Sargent, 2013; Scalia, 2008). The case of economy selected for this purpose is that of Pakistan. Interest in Pakistan as an economic and finance case is high because of a number of factors. For example it has been observed in the case of Pakistan that the Dollar has almost always appreciated against the rupee thus rendering the rupee weakened in the entire world and the debt of Pakistan increased by several folds. This makes government intervention in the stabilization of dollar a need for the economy however any government intervention by the government might appear to the investors as a sign of weakening of the economy and an artificial way to make the economy look better (Menkhoff, 2010). Considering the state of the economy of Pakistan, elements that may affect the inflation rate and the overall monetary system of the country is an important economic issue to be catered to. Specifically the influence of the American political and economic systems on the country is thought to have a profound impact on the stability and the growth the same for Pakistan. The question however that has been raised by this research is whether this "thought" impact can be empirically tested to have an actual impact on the performance of the financial markets of the country. For this purpose, the research is going to be working with the assumption of behavioral researchers that the perceptions of the investors have a strong impact on their investment decisions and that these investment decisions overall have an impact on the performance of the stock market (Cheng et al, 2000). Specifically in this research the following issues will be analyzed:

i) Analysis of how the foreign exchange system in Pakistan is structured and how often is an intervention by State Bank expected?

ii) How does the rate of dollar impact upon the expectations of the investors regarding the economy?

These issues are important to be considered because the role that government interventions play in investor decisions have not been studied and analyzed significantly in the available literature thus overall making the issue inconclusive and the research unhelpful for the practitioners. Conducting this research with focus on inconsistent and constantly corrected Pakistan's economy will be a significant addition to the existing research.

\subsection{Monetary Intervention}

\section{Literature Review}

According to Poytner (2013) well developed financial markets and advanced economies that have dependable and structured monetary systems typically following a floating exchange rate regime in which the policy makers allow the markets to take decide the foreign exchange rates. These flexible systems allow the monetary systems to be more independent and also make them less vulnerable to economic shocks (Jeanne, 2012). Having noted the virtues of a free flowing exchange rate the counter fact is also true that the policy makers believe that given the market information perfections (Fatum and Yamamoto, 2014) and the increasing 
inconsistency in market movements (Kumhof, 2010) exchange rates are seen to be driven away from their macroeconomic fundamentals (Reitz and Taylor, 2008). Humpage (2003, p. 7) says that,

"While similar information imperfections may affect other financial markets, government interventionists contend that the macroeconomic implications of even temporary exchange-market failures are great enough to warrant corrective actions."

Bailey et al (2000) note that one of the ways to deal with the deviation of foreign exchange movements from the macroeconomic fundamental can be solved through the fiscal policy and that the tool of monetary policy should not be used as it may have more adverse than good effects on the overall economy. Sarno and Taylor (2001) however note that fiscal policy may be too unresponsive and slow for the corrective actions that need to be taken in regards to the exchange rates and the resulting conditions that the economy is facing.

What needs to be noted then is how the corrective movements in the economy impact upon the perceptions of investors in the economy.

\section{Perceptions of Investors}

Fama(1970) notes that in efficient markets, the returns of the stock market will quickly adjust to the changes in the market including the interventions by the government as the investors will quickly respond to the new information available. Research by Hoffman, Post and Pennings (2012) shows that:the perceptions of the individual investors are affected by the risk taking behaviors especially during the seasons of financial crises. In regards to the impact that foreign exchange interventions have on the overall economy, Fatum and Pedersen (2009) suggest that small interventions exert no particular influence on the exchange rate and thus should not be considered a significant factor. Only the other hand, large interventions according to the author sees a strong reaction from the economy and therefore should be avoided as far as their implementation is concerned (Su et al, 2002).

\section{Methodology}

In order to conduct this research, a regression analysis (Eichengreen et al, 2002; Juhn and Mausro, 2002 and Alesina and Wagner, 2006) has been conducted between the stock market returns and the changes in the foreign direct investment as studied against the changes in the dollar rates when managed by the State Bank. For this purpose, secondary data has been collected from the sources including Press Releases of State Bank Pakistan, World Bank measures of investment in Pakistan and the KSE 100 index stock performance. The time period for this analysis is limited from 1971 to 2013 that is, ever since Pakistan's two wings separated. Through this research an empirical evidence of whether the Dollar stabilization process is beneficial to investment decision making in the economy will be seen.

\section{Data presentation and analysis \\ Dollar Value and amount of FDI}

In this analysis, dollar value and amount of investment by foreign investors in Pakistan are two variables. Dollar value is an independent variable while amount of investment is a dependent variable. The amount of foreign direct investment has been calculated as percentage of the GDP. The input of the analysis has come from the value of the regression coefficient, which manifests the degree of dependence of the amount of foreign investment in Pakistan on the value of dollar.

As the results show, the value of the regression coefficient is -.78 , and the value of y-intercept is approximately 113. The value of regression coefficient indicates that for $1 \%$ increase in the value of dollar against the value of rupee, the amount of foreign direct investment falls by .78 per unit. The dollar value and the amount of foreign investment are inversely related.

The above values represent the trend of the data since 1971, as collected from various regulatory authorities in Pakistan under the research methodology. The value of regression coefficient shows that over the years the amount of FDI has been directly linked to the changes in the exchange rates in Pakistan, caused by the state bank interventions in the foreign exchange market. If rupee depreciates against dollar, this is taken as a bad sign by the foreign investors in Pakistan and vice versa.

The value of regression coefficient answers many questions regarding the objectives of this research. This indicates that whenever the state bank of Pakistan intervened for dollar stabilization, it had a genuine impact on the economic perceptions of the investors. The value -.78 of regression coefficient shows the extent to which foreign direct investment in Pakistan is sensitive to the State bank's intervention in dollar stabilizations of the country.

Whenever state bank brought the value of dollar down by $1 \%$, its action resulted into .78 unit increase in the amount of FDI. As a result, economic growth took place, because foreign investment gave boost to local industry, and the cumulative effect of FDI led to fast-paced economic growth. 
Whenever dollar value decreases, foreign investors may feel that the country has accumulated reasonable foreign reserves and that the balance of payment is going to improve due to the decrease in the value of import bill. They may find this situation as ideal to invest, because of macroeconomic stability. They may also feel that low dollar value against rupee will boost local intermediary industries, because imports have become inexpensive.

The country where intermediate industries are great in number is found extremely attractive by the foreign investors, because these industries can ensure smooth, stable and sustainable supply chain to them. Similarly, fall in dollar value may be taken as an opportunity by the foreign investors to capitalize on the high interest rates of the country. A bulk of the foreign investment over the years has come in financial sector of Pakistan. More often than not, dollar falls due to the increase in the interest rate by the state bank of Pakistan. This increased interest rate entices foreign investors, because they can earn high profits by charging high interest rates to the borrowers.

The countries like China, India and Taiwan have recorded unprecedented GDP growth rates over the years, mainly due to foreign direct investment in their countries. These countries stabilized dollar, apart from controlling other factors, and as a result, FDI increased substantially. Pakistan could also use dollar stabilization as part of the FDI-led growth strategy. Though state bank intervened in many occasions to stabilize dollar through monetary policy, it failed in most of the occasions, as it could not control exogenous factors.

This is the reason why despite having the value of regression coefficient at .78 , that is, having higher dependence of the amount of FDI on dollar changes, the country could not drive in foreign direct investment.

Policy implications of the analysis of regression equation comprising of FDI amount and dollar rates are numerous. Government should take measures like bridging the balance of payment gap, improving foreign reserves by taking loans from international lenders, or increasing the amount of foreign remittances, to bring the value of dollar down. These changes would increase the amount of foreign direct investment by many folds, because the statistical analysis using the regression equation has confirmed this trend.

The conclusion from the analysis is that economic perceptions of the foreign investors in Pakistan are heavily influenced by the dollar stabilization endeavors taken by the government of Pakistan.

\section{Dollar value and Stock market returns}

In this analysis, dollar value is an independent variable and the amount of stock market returns is a dependent variable. The amount of stock market returns has been calculated as percentage of the average market capitalization during the year 1990. The degree of dependence of the stock market returns on the value of dollar has been elaborated in the following lines. If the degree of dependence is higher, that means perceptions of the investors in stock exchanges of Pakistan are affected by the dollar stabilization endeavors of the government of Pakistan.

The results of the regression analysis show that the degree of dependence of stock market returns on dollar values is not as strong as in the case of dollar and foreign direct investment. This is indicated by the value of regression coefficient, which is -.26 . The negative sign shows that the relation is inverse, which means if dollar value decreases against rupee, the stock market returns increase.

To what extent the stock market returns increase by the decrease in the value of dollar is indicated by the value .26 , which says if dollar falls by $1 \%$, the stock market returns will be increased by .26 . To make it more clear, if the dollar value decreases by one percent and reaches 98 from 98.98, then the percentage of the stock market returns, provided the existing percentage is 10 , will increase to 10.26. It must be reiterated here that the value of stock market returns has been measured as percentage of the total market capitalization of the stock market during the year 1990 .

The reverse of the relationship is that if dollar increases by $1 \%$, the percentage of the stock market returns to the average market capitalization of the year 1990 will be decreased by .26. Since the regression analysis has been done on the secondary data taken from the documents of relevant government authorities, this shows the empirical value of the trend that the economy of Pakistan has taken over the years.

Whenever the state bank of Pakistan stepped in to regularize the value of dollar, it had an effect on the stock exchanges of the country. Though the effect was not drastic, but it changed the course of the activities of the capital markets more often than not. The reasons behind this can be the inherent sensitivity of the stock market returns in Pakistan to dollar value. If the dollar increases against rupee, investors may feel that the imports will become expensive, affecting the industries that depend on imports. Similarly, the rise in dollar leads to a substantial increase in the oil import bill of the country. Almost 160,000 tones of petroleum is imported by Pakistan every month. The increase in oil import bill negatively affects all sectors of the economy. This can be one of the reasons why, when dollar appreciates, the stock market returns go down. The opposite is true when dollar falls against the value of rupee. 
The policy implications of the regression coefficient value of .26 are immense. The state bank can estimate in advance the behavior of stock exchange if it plans to increase or decrease the value of dollar in future. Prior determination of the stock market returns can allow the state bank to better evaluate the impact of its different policies on the economy of the country. It will permit state bank to decide when intervention for dollar stabilization is good for the economy, and when it is not.

All-in-all, the quantitative analysis shows that there is a considerable degree of dependence of FDI and stock market returns on the dollar rates. However, the dependence of the amount of FDI is higher than the dependence of the stock market returns on the dollar value.

\section{RESULTS}

The results of the regression analysis have a clear linkage with the findings of the literature review made in this research. According to Tobin (1980), countries should tax foreign exchange transactions heavily in order to keep their exchange rate stable. If the government of Pakistan taxes dollar transactions, then the value of dollar shall become stable, as per the viewpoint of Tobin (1980). However, if the regression value of -.78, which signifies the dependence of the amount of FDI on dollar value in Pakistan, is considered, the suggestion given by Tobin (1980) should not be accepted.

His suggestion is incompatible with the dynamics of the economy of Pakistan, as revealed by the regression analysis. Instead of stability, the government of Pakistan should intervene to reduce the value of dollar against the rupee as much as possible, because $1 \%$ fall in the dollar value produces $.78 \%$ rise in the foreign direct investment in the country. If the dollar is kept stable by taxing the foreign exchange transaction, then the benefits of this unique characteristic of the economy of Pakistan will be lost by the government. However, the state bank of Pakistan should consider its inflation objectives, while trying to reduce the value of dollar against rupee, as discussed in the literature review.

\section{Conclusion}

Research in the field of finance shows that investors take into account a variety of factors while determining the investment decisions and the risk and return per stock (Rogers and Siklos, 2003; Scalia, 2008). One of the factors that have not been researched upon in this regards is government intervention and how it impacts on the risk and return of particular stocks. This research has been developed to fill that gap between the needed and the current state of financial literature. The findings of the research show that for the economy of Pakistan reacts positively to the intervention by the government to maintain and neutralize the dollar and thus in order to sustain the economy, the State Bank needs to constantly intervene until the economy matures to achieve fundamental and theorized economic movements.

\section{References}

[1]. Alesina, A. and Wagner, A. (2006). Choosing (and reneging on) exchange rate regimes, Journal of the European Economic Association, Working paper 9809.

[2]. Cheng et al. (2000). Pricing dynamics of index options and index futures in Hong Kong before and during the Asian financial crisis, Journal of Futures Markets, Vol. 20 (2), pp. 145 - 166.

[3]. Eichengreen et al. (2002). Original Sin, the pain, the mystery and the road to redemption", prepared for the conference "Currency and Maturity Matchmaking, USA: Inter American Development Bank.

[4]. Fama, E. (1970). Efficient capital markets: a review of theory and empirical work, Journal of Finance, Vol. 25, pp. 383 - 417

[5]. Fatum, R. and Yamamoto, Y. (2014). Large versus small foreign exchange interventions, Journal of Banking and Finance, Vol. 43, pp. $114-123$

[6]. Fatum, R. and Pedersen, J. (2009). Journal of Economic Literature, Vol. 39, pp. 11 - 20

[7]. Hoffman, A., Post, T. and Pennings, J. (2012). Individual investor perceptions and behavior during the financial crisis, Journal of Banking and Finance, Vol. 37 (1), pp. $60-74$

[8]. Humpage, O. (2003). Government Intervention in the Foreign Exchange Market, Working Paper, 3-15. FBRC.

[9]. Hsu et al. (2012). Risk an Uncertianty analysis in the planning stages of a risk decision making process, Natural Hazards, Vol. 61 , pp. $1355-1365$.

[10]. Juhn, G. and Mauro, P. (2002). Long-Run determinants of exchange rate regimes: a simple sensitivity analysis. International Monetary Fund, Working Paper 02/104.

[11]. Kumhof, M. (2010). On the theory of sterilized foreign exchange intervention, Journal of Economic Dynamics and Control, Vol. 34 (8), pp. $1403-1420$

[12]. Jeanne, O. (2012). Capital Account Policies and the Real Exchange Rate, NBER Working Paper, No. 18404.

[13]. Mansini, A. and Menichetti, E. (2012). The impact of behavioural factors in the renewable energy investment decision making process: Conceptual framework and empirical findings, Energy Policy, Vol. 40, pp. 28 - 38

[14]. Menkoff, L. (2009). HIGH-FREQUENCY ANALYSIS OF FOREIGN EXCHANGE INTERVENTIONS: WHAT DO WE LEARN?, Journal of Economic Surveys, Vol. 24 (1), pp. 85 - 112

[15]. Poytner, T. (2012). Multinational Enterprises and Government Intervention, USA: Routledge.

[16]. Rogers, J. and Siklos, P. (2003). Foreign exchange market intervention in two small open economies: the Canadian and Australian experience, Journal of International Management, Vol. 22 (3) pp. $393-416$

[17]. Scalia, A. (2008). Is foreign exchange intervention effective? Some microanalytical evidence from the Czech Republic, Journal of International Money and Finance, Vol. 27 (4), pp. $529-549$ 
The impact of government intervention in Dollar stabilization on the economic perceptions of...

[18]. Su et al. (2002). The impact of government intervention on stock returns: Evidence from Hong Kong, International Review of Economics \& Finance, Vol. 11 (3), pp. 277 - 297.

[19]. Sargent, T. (2013). Rational Expectations and Inflation, $3^{\text {rd }}$ Ed. USA: Princeton University

[20]. Sarno, L. and Taylor, M. (2001). Official Intervention in the Foreign Exchange Market: Is It Effective and, If so, How Does It Work? Journal of Economic Literature Vol. 39 (3), pp. 839 - 868.

[21]. Turskis et al. (2011). Multiple Criteria Decision Making (MCDM) Methods in Economics: An Overview, Technological and Economic Development of Economy, Vol. 2, pp. 397 - 427

\section{Appendix}

Quantitative analysis

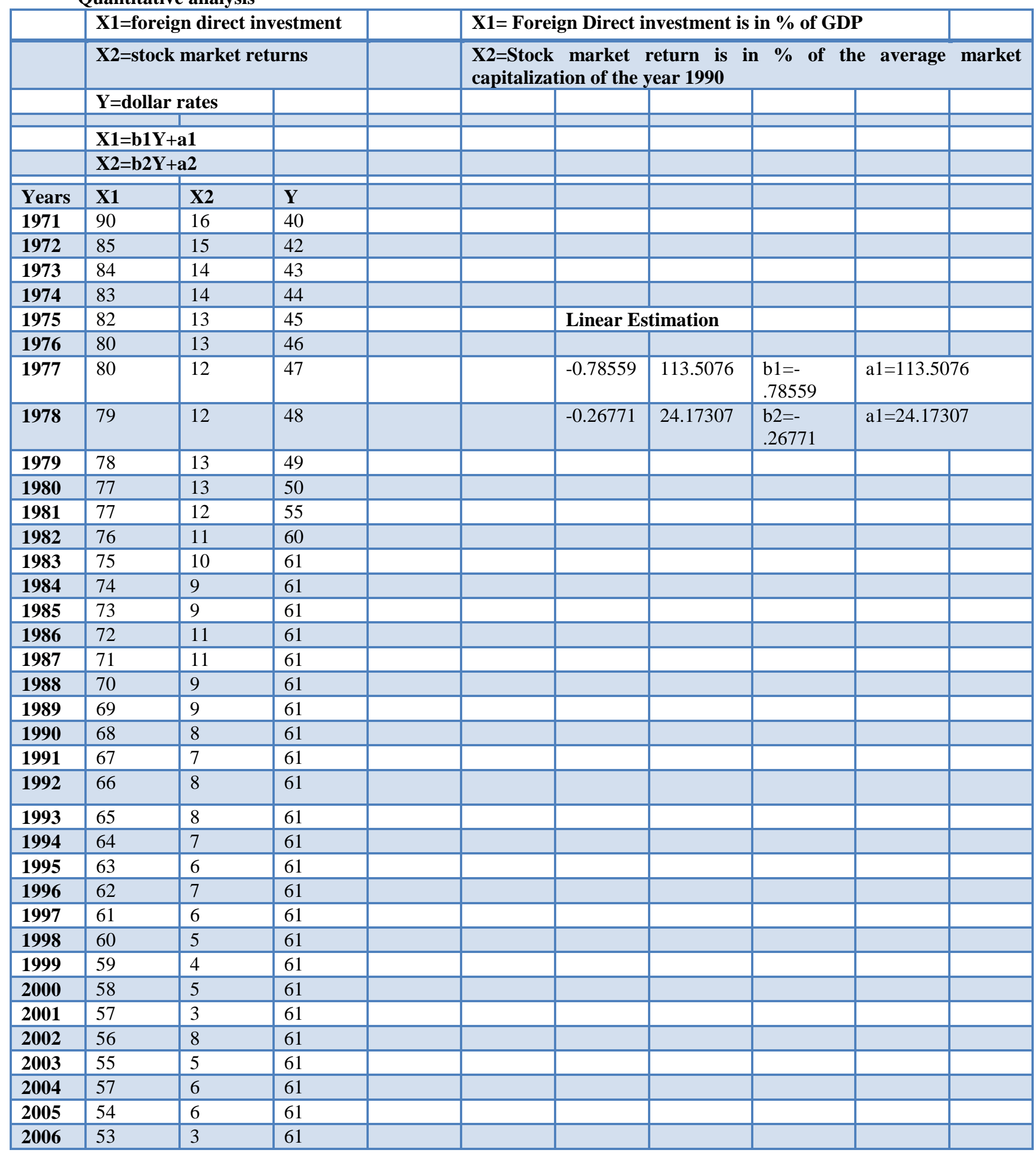


The impact of government intervention in Dollar stabilization on the economic perceptions of...

\begin{tabular}{|l|l|l|l|l|l|l|l|l|l|l|}
\hline $\mathbf{2 0 0 7}$ & 52 & 4 & 61 & & & & & & & \\
\hline $\mathbf{2 0 0 8}$ & 51 & 3 & 65 & & & & & & & \\
\hline $\mathbf{2 0 0 9}$ & 50 & 3 & 70 & & & & & & & \\
\hline $\mathbf{2 0 1 0}$ & 49 & 2 & 80 & & & & & & & \\
\hline $\mathbf{2 0 1 1}$ & 48 & 2 & 90 & & & & & & & \\
\hline $\mathbf{2 0 1 2}$ & 47 & 2 & 95 & & & & & & & \\
\hline $\mathbf{2 0 1 3}$ & 46 & 1 & 100 & & & & & & & \\
\hline
\end{tabular}

